\title{
Let there be water: How hydration/dehydration reactions accompany key Earth and life processes 웅
}

\author{
Alberto Vitale Brovarone ${ }^{1,2, *, \S}$, Christopher J. Butch ${ }^{3}$, Alessandra Ciappa $^{4}$, \\ Henderson J. Cleaves II ${ }^{5,6,7}$, Agnès Elmaleh ${ }^{2}$, Manuele Faccenda ${ }^{8}$, Maureen Feineman', \\ Jörg HermanN ${ }^{10}$, Fabrizio Nestola ${ }^{8, \dagger}$, Angelina Cordone ${ }^{11}$, and Donato Giovannelli ${ }^{4,5,11,12,13, \$}$
}

\author{
${ }^{1}$ Dipartimento di Scienze della Terra, Università degli Studi di Torino, 10125 Torino, Italy \\ ${ }^{2}$ Sorbonne Université, Muséum National d'Histoire Naturelle, UMR CNRS 7590, IRD, Institut de Minéralogie, de Physique des \\ Matériaux et de Cosmochimie, IMPMC, 75005 Paris, France \\ ${ }^{3}$ Department of Biomedical Engineering, Nanjing University, Nanjing, China \\ ${ }^{4}$ Nano-Tech SpA, via d'Ancona 73/A, 60127 Osimo, Italy \\ ${ }^{5}$ Earth-Life Science Institute, Tokyo Institute of Technology, 2-12-1-IE-1 Ookayama, Meguro-ku, Tokyo 152-8550, Japan \\ ${ }^{6}$ Blue Marble Space Institute for Science, 1001 4th Avenue, Suite 3201, Seattle, Washington 98154, U.S.A. \\ ${ }^{7}$ Institute for Advanced Study, 1 Einstein Drive, Princeton, New Jersey 08540, U.S.A. \\ ${ }^{8}$ Dipartimento di Geoscienze, Università di Padova, 35131 Padova, Italy \\ ${ }^{9}$ Department of Geosciences, Penn State 508 Deike Building, University Park, Pennsylvania 16802, U.S.A. \\ ${ }^{10}$ Institute of Geological Sciences, University of Bern, 3012 Bern, Switzerland \\ ${ }^{11}$ Department of Biology, University of Naples "Federico II", via Cinthia, 80126, Naples, Italy \\ ${ }^{12}$ Department of Marine and Coastal Science, Rutgers University, 71 Dudley Road, 08901 New Brunswick, New Jersey, U.S.A. \\ ${ }^{13}$ Institute of Marine Biological and Biotechnological Resources, National Research Council of Italy, CNR-IRBIM, \\ 1.go Fiera della Pesca, 60121, Ancona, Italy
}

\begin{abstract}
Water plays a key role in shaping our planet and making life possible. Given the abundance of water on Earth's surface and in its interior, chemical reactions involving water, namely hydration and dehydration reactions, feature prominently in nature and are critical to the complex set of geochemical and biochemical reactions that make our planet unique. This paper highlights some fundamental aspects of hydration and dehydration reactions in the solid Earth, biology, and man-made materials, as well as their connections to carbon cycling on our planet.

Keywords: Hydration/dehydration reactions in the solid Earth, hydration/dehydration in biology, hydration/dehydration in modern society, water cycle; Earth in Five Reactions: A Deep Carbon Perspective
\end{abstract}

\section{INTRODUCTION}

Hydration/dehydration reactions are common on Earth, because it is a liquid water-rich planet, and are intrinsic to the geoand biochemical processes that have shaped Earth's evolution, habitability, and biosphere (Rubey 1951). Hydration reactions are chemical reactions in which a substance uptakes the equivalent of a water molecule $\left(\mathrm{H}_{2} \mathrm{O}\right)$; dehydration reactions are the converse reaction, the loss of a water molecule. The water formula-equivalent may be lost or gained in a concerted or unconcerted manner, with protonation and deprotonation occurring in series. As an example, a simple hydration reaction particularly relevant to this collection is the formation of carbonic acid from $\mathrm{CO}_{2}$ and $\mathrm{H}_{2} \mathrm{O}$ :

$$
\mathrm{H}_{2} \mathrm{O}+\mathrm{CO}_{2} \rightarrow \mathrm{H}_{2} \mathrm{CO}_{3} \text {. }
$$$$
\text { water }+ \text { carbon dioxide } \rightarrow \text { carbonic acid }
$$

This reaction is important in ocean chemistry, geological cycling and biology on Earth in a multitude of ways, several of which are presented in the following sections.

\footnotetext{
* E-mail: alberto.vitale@unito.it. Orcid 0000-0001-8892-9567.

+ Orcid 0000-0002-4875-5125.

† Orcid 0000-0001-7182-8233.

$\S$ Special collection papers can be found online at http://www.minsocam.org/MSA/ AmMin/special-collections.html.

Open access: Article available to all readers online.
}

Hydration/dehydration reactions play a pivotal role in the dynamics of the solid Earth (the first part of this review), in life (the second part), and in modern society (the final part). In this review we summarize some important features of hydration/dehydration reactions and how they have participated in the evolution of carbon's behavior in the context of our planet, its biology, and modern society.

\section{HYDRATION/DEHYDRATION REACTIONS IN THE SOLID EARTH}

In Earth science, the term water commonly includes a range of $\mathrm{H}$-bearing compounds such as molecular $\mathrm{H}_{2} \mathrm{O}$, hydroxyl groups $\left(\mathrm{OH}^{-}\right)$, or simply $\mathrm{H}$. This water can be incorporated in rocks in multiple ways, such as in hydrous minerals, in nominally anhydrous minerals, in fluid inclusions, or adsorbed onto mineral surfaces without entering the structure of the mineral. Hydrous minerals can host water as either molecular $\mathrm{H}_{2} \mathrm{O}$ or $\mathrm{OH}^{-}$, or in both forms, and include a large variety of mineral groups such as clays, amphiboles, micas, chlorite, serpentines, lawsonite, and many others, some capable of hosting more than $10 \mathrm{wt} \%$ water. Among the most important hydrous minerals is serpentine (13 $\mathrm{wt} \%$ bond water), which forms through the hydration of olivine, ranging in composition from $\mathrm{Mg}_{2} \mathrm{SiO}_{4}$ to $\mathrm{Fe}_{2} \mathrm{SiO}_{4}$, as described by the model reaction: 


$$
\begin{aligned}
& 2 \mathrm{Mg}_{2} \mathrm{SiO}_{4}+3 \mathrm{H}_{2} \mathrm{O} \rightarrow \mathrm{Mg}_{3} \mathrm{Si}_{2} \mathrm{O}_{5}(\mathrm{OH})_{4}+\mathrm{Mg}(\mathrm{OH})_{2} . \\
& \mathrm{Mg} \text {-olivine }+ \text { water } \rightarrow \text { serpentine }+ \text { brucite }
\end{aligned}
$$

The serpentinization reaction may also involve oxidation of $\mathrm{Fe}^{2+}$ in iron-containing olivine and other minerals such as pyroxenes, and its partitioning among minerals such as magnetite, brucite, and serpentine, for example (Andreani et al. 2013; Klein et al. 2009):

$3 \mathrm{Fe}_{2} \mathrm{SiO}_{4}+2 \mathrm{H}_{2} \mathrm{O} \rightarrow 2 \mathrm{Fe}_{3} \mathrm{O}_{4}+3 \mathrm{SiO}_{2}+2 \mathrm{H}_{2}$.

$\mathrm{Fe}$-olivine + water $\rightarrow$ magnetite + dissolved silica + di-hydrogen

During serpentinization, hydration is not only important for the incorporation of water into the solid Earth, but also generates natural chemical energy sources such as $\mathrm{H}_{2}$ and affects carbon redox cycling, most notably the abiotic conversions of $\mathrm{CO}_{2}$ into hydrocarbons, reactions that have analogs in biochemistry (Schulte et al. 2006; Russell et al. 2010). Such reactions might have played a role early in life's emergence, and they are thought to occur widely on solar system bodies and the sites where they occur may be good targets for planetary exploration and the search for extraterrestrial life (e.g., Schrenk et al. 2013).

Nominally anhydrous minerals (NAMs) are minerals that do not contain water in their formula by definition but where $\mathrm{H}$ or, more rarely molecular $\mathrm{H}_{2} \mathrm{O}$, can be incorporated in structural defects such as cation vacancies and charge deficiencies (e.g., Smyth et al. 2003). Typical examples are olivine, pyroxenes, and garnet, all of which can host several hundred parts per million of water.

The following sections summarize the cycle of water in the solid Earth and the exchanges among different geological water reservoirs. Free water hosted in rocks, i.e., pore water or fluid inclusions, will not be discussed.

\section{Early hydration on Earth}

The same mechanisms that brought water to Earth are closely linked to the ones that brought carbon, as hydrogen and carbon are volatile elements in protoplanetary disk contexts. Both are found in small amounts within inner solar system bodies $(\leq 2.5-3 \mathrm{AU}$, Morbidelli et al. 2012; Gail and Trieloff 2017). However, large differences between hydrogen and carbon chemistries - including hydration processes (see below) and organic chemistry (Henning and Semenov 2013) - induce differential behaviors at every step of their incorporation into rocks. Starting with nebular processes, retention of water vapor in the hot, terrestrial planet forming region may occur through adsorption onto silicates (e.g., forsterite) as supported by atomistic simulations (e.g., King et al. 2010). The predicted adsorption of dissociated water to silicate surfaces opens the possibility for hydration reactions in condensates (King et al. 2010).

A large part of Earth's water (and carbon) likely came from outer solar system sources. This may have been delivered by the inward drift of hydrated silicates (Ciesla and Lauretta 2005) or more likely by accretion of either carbonaceous chondrite-like bodies, or comets, both enriched in $\mathrm{H}$ and $\mathrm{C}$ (see reviews by Morbidelli et al. 2012; Marty et al. 2016; O'Brien et al. 2018). The speciation of hydrogen (either water ice or hydrated phases) in impactors is an important parameter influencing dehydration/ hydration during transport and impact. In the most water-rich CI and CM carbonaceous chondrites, hydrogen is mostly contained in serpentine and smectite ( $\mathrm{H}$ in organic matter is only a small fraction of the bulk) that likely formed in the meteorites' parent bodies through melting of accreted ices (e.g., Brearley 2006). Asteroidal water-rock interactions are thus an example of the early importance of serpentinization in the solar system. Iron, abundant in these undifferentiated systems, is initially present as $\mathrm{Fe}^{0}$ in alloys and $\mathrm{Fe}^{2+}$ in sulfides and ferromagnesian silicates, and as both $\mathrm{Fe}^{2+}$ and $\mathrm{Fe}^{3+}$ in serpentine (e.g., Zega et al. 2003). In the absence of substantial amounts of oxygen, this suggests $\mathrm{H}_{2}$ production through water reduction coupled to iron oxidation and its variable incorporation to serpentines at low temperatures, presenting an analogy with terrestrial serpentinization (e.g., Andreani et al. 2013).

How do chondritic materials dehydrate during impacts? Most studies have focused on magnesian serpentine, and shock dehydration of antigorite occurs at much higher pressures and temperatures than static dehydration due to dynamic effects (see e.g., Sekine et al. 2012). Much remains to be understood about the partitioning of water between the atmosphere and the solid Earth and hydration/ dehydration competition during impacts, likely frequent during late accretion (Morbidelli et al. 2012; O'Brien et al. 2018). It is important to evaluate these predicted inputs together with possible earlier and deep hydration of terrestrial building blocks, through nebular inheritance. Indeed, the amount and distribution of water and other volatile species including $\mathrm{C}$-bearing species at early stages would have profoundly affected differentiation processes (Elkins-Tanton 2012; Izodoro et al. 2013; see also Dasgupta 2013, for the case of carbon).

\section{Hydration and weathering at the hydrosphere-lithosphere interface}

The hydration of $\mathrm{CO}_{2}$ to form $\mathrm{H}_{2} \mathrm{CO}_{3}$ (reaction 1) drives several other important reactions, both on the continents and in the ocean, that collectively form the carbonate-silicate cycle (Fig. 1; Stewart et al. 2019). These reactions are significant for the transfer of hydrogen and carbon between Earth's major reservoirs. For example, silicate weathering removes $\mathrm{H}_{2} \mathrm{O}$ and $\mathrm{CO}_{2}$ from the atmosphere-hydrosphere system and sequesters these volatiles in solid rock. Chemical weathering of silicates is enhanced by mountain-building events (Fig. 1), wherein silicate rocks are uplifted and exposed to mechanical weathering processes. As a result, a positive feedback may develop between orogenesis and removal of $\mathrm{CO}_{2}$ from the atmosphere by silicate weathering (Raymo et al. 1988; Macdonald et al. 2019).

Since plagioclase feldspar is the most abundant mineral in the Earth's crust, and since Ca-feldspar appears to be the most rapidly weathered Earth surface mineral (Kump et al. 2000), weathering of anorthite is used here as a representative example of a silicate weathering reaction. The same principles can be applied to other hydration reactions such as serpentinization (Kelemen et al. 2011). The net result of anorthite weathering can be expressed as:

$2 \mathrm{H}_{2} \mathrm{O}+\mathrm{CO}_{2}+\mathrm{CaAl}_{2} \mathrm{Si}_{2} \mathrm{O}_{8} \rightarrow \mathrm{Al}_{2} \mathrm{Si}_{2} \mathrm{O}_{5}(\mathrm{OH})_{4}+\mathrm{CaCO}_{3}$. (4) water + carbon dioxide + anorthite $\rightarrow$ kaolinite + calcium carbonate

in which $\mathrm{H}_{2} \mathrm{O}$ and $\mathrm{CO}_{2}$ in the atmosphere react with anorthite to produce kaolinite (clay) and calcium carbonate, which can then be buried and/or subducted into the deep Earth. 


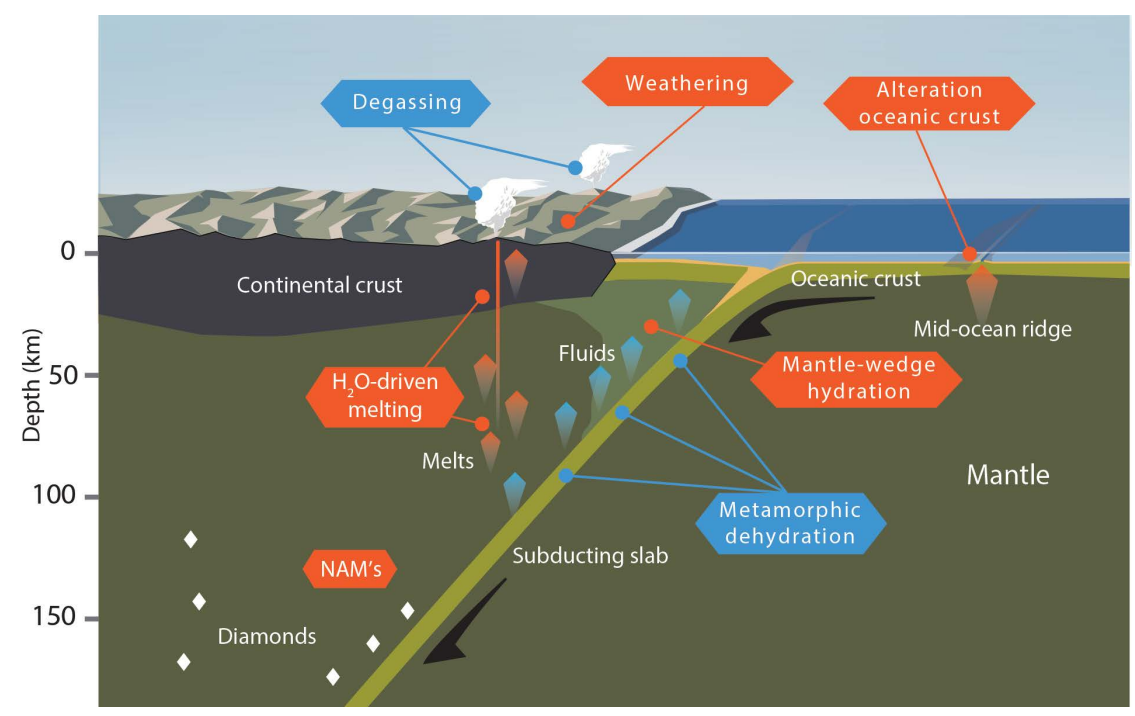

Figure 1. Geodynamics of hydration/ dehydration. The orange labels refer to processes of hydration and water sequestration in rocks and magmas, whereas the blue labels refer to processes of dehydration or water release from rocks and magmas. Modified after Figure 1 in $\mathrm{Li}$ et al. (2019) by Josh Wood/Deep Carbon Observatory.

An additional outcome of note is that calcium carbonate precipitation exchanges $\mathrm{Ca}^{2+}$ for two $\mathrm{H}^{+}$ions in carbonic acid, which may contribute to lowering the $\mathrm{pH}$ of the ocean. The net effect of adding acid equivalents to the oceans is commonly referred to as ocean acidification, although it is worth noting that the ocean as a whole is slightly basic $(\mathrm{pH}>8)$, and rather than causing ocean water to become acidic, the addition of $\mathrm{H}^{+}$ ions drives the $\mathrm{pH}$ of the oceans to a slightly less basic value, partially due to carbonate/bicarbonate buffering. To maintain bicarbonate equilibrium, some excess $\mathrm{H}^{+}$reacts with $\mathrm{CO}_{3}^{2+}$. This removes carbonate ions from the ocean, inhibiting the formation of $\mathrm{CaCO}_{3}$ (Kump et al. 2000). Thus, the $\mathrm{pH}$ of the ocean is buffered by marine carbonates, but if the $\mathrm{pH}$ drops too abruptly, not only will new carbonate precipitation be inhibited but existing carbonate-based ecosystems, such as nanoplankton and coral reefs, may begin to dissolve (Kump et al. 2009). So, while the oceans do have the capacity to act as an atmospheric $\mathrm{CO}_{2}$ sink, this atmospheric buffering may come at a cost to marine life (Caldeira and Wickett 2003).

Hydration and companion carbonation of silicate minerals also represent a fundamental means to transfer water and carbon from oceans into the solid Earth (Fig. 1; Stewart et al. 2019). Alteration of mantle rocks (serpentinization, reaction 2) and mafic oceanic crust can lead to the formation of hydrous minerals such as serpentine, brucite, amphiboles, smectites, chlorites, epidotes. The amount of water (and carbon) incorporated into the oceanic lithosphere through hydration decreases with depth, and strongly depends on the structure and composition of the oceanic lithosphere. Global budgets for the sequestration of chemically bound $\mathrm{H}_{2} \mathrm{O}$ in the oceanic lithosphere are on the order of $10^{12}$ $\mathrm{kg} / \mathrm{yr}$, i.e., about one billionth of the total ocean volume per year (Faccenda 2014; Jarrard 2003).

\section{Recycling of water through subduction zone metamorphism}

The altered oceanic crust is buried along subduction zones, providing a mechanism for transporting water and carbon into the mantle (Fig. 1). Aqueous fluids are then produced by dehydration reactions involving the hydrous minerals introduced in the previous section during burial and heating of the oceanic crust (Fig. 1). Sediments play a quantitatively minor role for water storage (Faccenda 2014; Jarrard 2003) and thus are not considered here. In the altered mafic oceanic crust, key hydrous minerals formed by progressive reequilibration of the weathering products of the oceanic crust (see previous section) during burial in the subduction zone include chlorite, amphibole, epidote, and lawsonite. With rising temperature and pressure, these hydrous minerals are subjected to dehydration reactions that generally occur over an extended temperature range $\left(300-800{ }^{\circ} \mathrm{C}\right)$ characteristic of the forearc-to-subarc of subducting slabs (Fig. 1). This leads to a gradual release of water that is most pronounced at fore-arc conditions, up to $80 \mathrm{~km}$ depth (Schmidt and Poli 1998). At subarc conditions ( $~ 80-150 \mathrm{~km}$ depth of the slab) mafic rocks have mainly converted to an anhydrous rock called eclogite that dominantly consists of garnet and omphacite. In contrast, in subducted hydrated mantle, there are only three major dehydration reactions occurring over restricted temperature intervals of about $20-30{ }^{\circ} \mathrm{C}$ and correspond to the release of $\sim 2 \mathrm{wt} \% \mathrm{H}_{2} \mathrm{O}$ (60-80 km depth), 5-8 wt\% $\mathrm{H}_{2} \mathrm{O}$ (80-120 km depth), and 1-3 wt $\% \mathrm{H}_{2} \mathrm{O}(100-150 \mathrm{~km}$ depth, respectively (Padrón-Navarta et al. 2013; Ulmer and Trommsdorff 1995; Fumagalli and Poli 2005).

The release of aqueous fluids through dehydration reactions also controls the fate of subducted carbon, by enhancing decarbonation reactions (Gorman et al. 2006; Stewart et al. 2019; Edmonds et al. 2020), carbonate dissolution, and melting of carbonate-bearing rocks at the top of the slab (Kelemen and Manning 2015; Hermann and Spandler 2008).

The aqueous fluids released by dehydration reactions will migrate, initially within the slab and eventually through the overlying mantle wedge (Fig. 1). Moreover, fluid-rock interactions during this percolation may result in hydration of slab- and mantle wedge-forming rocks and re-sequestration of part of the previously released aqueous fluids (King et al. 2003; Vitale Brovarone and Beyssac 2014; Hyndman and Peacock 2003; Wada et al. 2012). 


\section{Role of water in new crust formation}

As aqueous fluids and hydrous melts leave the subducted slab at subarc depths, they encounter higher temperatures due to the inverted thermal gradient at the top of the slab. Water-fluxed partial melting of the mantle occurs a few kilometers above the subducted slab, when temperatures exceed about $1025^{\circ} \mathrm{C}$ and melt fractions increase until the hottest part of the mantle wedge is reached (Green 2015). The resulting hydrous basalts to basaltic andesites ascend to form new continental crust (Fig. 1) (Grove and Kinzler 1986). Compared to mid-ocean ridge basalts (MORB) these arc basalts are enriched in $\mathrm{H}_{2} \mathrm{O}$ and a suite of incompatible trace elements extracted by the fluid phase from the subducted slab (Hawkesworth et al. 1993). Olivine-hosted melt inclusions suggest that primitive arc magmas contain about 4-6 wt\% $\mathrm{H}_{2} \mathrm{O}$ (Plank et al. 2013; Roggensack et al. 1997). Water strongly affects the way the basaltic magmas differentiate. The presence of water promotes amphibole crystallization and drives plagioclase to more anorthite-rich compositions. Due to the elevated oxygen fugacity in arc magmas, magnetite forms relatively early during this differentiation. Together these three processes lead to a pronounced enrichment of $\mathrm{SiO}_{2}$ and to a differentiation producing voluminous amounts of granites (Ulmer et al. 2018). Additionally, the liberation of $\mathrm{H}_{2} \mathrm{O}$ during the crystallization of hydrous magmas and the heat input by mafic underplating promotes partial melting in the lower crust, providing an additional process for producing granites that can migrate upward to form highly differentiated upper crust (Chappell and White 1992).

The low density of such upper continental crust is the basis for the establishment of stable continental crust that is no longer subducted and that emerges above sea level: "No water, no granites - no oceans, no continents" (Campbell and Taylor 1983). Weathering of emerged continents provides a means to transfer $\mathrm{H}_{2} \mathrm{O}$ from the hydrosphere to the lithosphere and an important feedback mechanism to stabilize atmospheric $\mathrm{CO}_{2}$ concentrations (see the section Hydration and weathering at the hydrosphere-lithosphere interface above). Thus, the presence of water on Earth is not only essential for the development of life itself, but it also creates variable habitats such as continents and oceans and helps to regulate Earth's climate.

\section{Hydration in the deep Earth}

Not all $\mathrm{H}_{2} \mathrm{O}$ is recycled back to the Earth's surface via fore-arc dehydration reactions and arc magmatism. Trace amounts of $\mathrm{H}_{2} \mathrm{O}$ are measured in "nominally anhydrous minerals" (NAMs) such as olivine, pyroxene, and garnet in point defects (e.g., Demouchy and Bolfan-Casanova 2016). The investigation of eclogite facies garnet (containing up to $130 \mathrm{ppm}$ water) and omphacite (containing up to $3000 \mathrm{ppm}$ water) that formed from hydrous phases by dehydration reactions showed that small amounts of water are retained in the subducted oceanic crust (Katayama et al. 2006; Smyth et al. 1991). Also the interaction of slab-derived fluids with the mantle wedge will lead to the incorporation of traces of $\mathrm{H}_{2} \mathrm{O}$ in olivine and pyroxenes. Experiments have shown that water in olivine in the mantle wedge increases with increasing pressure and temperature and ranges from 20-200 ppm $\mathrm{H}_{2} \mathrm{O}$ (Padrón-Navarta and Hermann 2017). At much higher pressures (i.e., $12 \mathrm{GPa}$ ) it is well known that olivine can host up to 10000 ppm $\mathrm{H}_{2} \mathrm{O}$ (Smyth and Jacobsen 2006). However, the deepest hydrated systems reported so far are related to diamonds and their mineral or fluid inclusions (i.e., Pearson et al. 2014; Smith et al. 2016, 2018). A possible reaction occurring at depths between 525 and $660 \mathrm{~km}$ (in the lower transition zone) involves the mineral ringwoodite (idealized formula $\mathrm{Mg}_{2} \mathrm{SiO}_{4}$ ), which was found as an inclusion within a Brazilian diamond (Pearson et al. 2014) containing about $1.4 \%$ wt $\mathrm{H}_{2} \mathrm{O}$. For such minerals, the hydration mechanism would include protonation of oxygen sites (hydroxyl, $\mathrm{OH}^{-}$) associated with the vacant and partially vacant octahedral sites, $\left[\mathrm{V}_{\mathrm{Mg}}(\mathrm{OH})_{2}\right]^{x}, \mathrm{Mg}^{2+}$ substitution for $\mathrm{Si}^{4+}$ on the tetrahedral site, $\left[\mathrm{Mg}_{\mathrm{Si}}(\mathrm{OH})_{2}\right]^{x}$, tetrahedral silicon vacancies with a hydrogarnet type defect, $\left[\mathrm{V}_{\mathrm{Si}}(\mathrm{OH})_{4}\right]^{x}$, and defects on tetrahedral edges, $\left[\mathrm{Mg} / \mathrm{Fe}^{2+} / \mathrm{Fe}_{\mathrm{Si}}^{3+}(\mathrm{OH})_{2}\right]^{x}$ (see Thomas et al. 2015 and references therein). Further evidence of hydration at great mantle depths related to diamonds are the fluid jackets found between the diamond host and the inclusions. Such jackets are made by molecular hydrogen $\left(\mathrm{H}_{2}\right)$ and methane $\left(\mathrm{CH}_{4}\right.$, Smith et al. 2016, 2018). Most recently, the presence of Ice-VII-a cubic crystalline form of ice - was reported in super-deep diamonds (Tschauner et al. 2018).

\section{Hydration/dehydration and Earth's dynamics}

It is widely accepted that water plays a fundamental role in mantle convection and its surface expression, plate tectonics (Fig. 1). At shallow depths, water reacts with dry minerals of the oceanic lithosphere to generate hydrous phases that have substantially lower mechanical strength than the dry counterparts (Escartin et al. 2001; Hilairet et al. 2007). During subduction, the hydrous minerals become progressively unstable releasing fluids that further lubricate the plate boundary. As a consequence, the mechanical weakening associated with hydrous minerals and the subsequent release of water is considered to be a critical ingredient for the relative movement of rigid blocks like the tectonic plates and hence the persistence of plate tectonics on a cooling, Earth-like planet.

At higher temperatures, where hydrous minerals are no longer stable, the incorporation of water (or more properly hydrogen equivalents) as hydroxyl point defect speeds up the kinetics of transport properties in NAMs because the incorporation of $\mathrm{OH}$ is charge balanced by the creation of vacancies, on the concentration of which most diffusive processes depend (Bolfan-Casanova 2005). As a result, water (hydrogen) increases the tendency of NAMs to creep, either by increasing the concentration of point-defects (i.e., cation vacancies) that, at high temperatures typical of the external portions of subducting slabs, enhances rates of species diffusion (diffusion creep) and dislocation climb (power-law creep), or, at low temperatures typical of slab cores, by reducing the Peierls stress/barrier to kink migration and thus enhancing dislocation glide (exponential-creep) (Karato 2006; Kohlstedt 2006). For instance, the addition of $0.1 \mathrm{wt} \% \mathrm{H}_{2} \mathrm{O}$ can reduce the effective viscosity of wet NAMs by a factor of $10^{3}$ or more (Karato 2006). It has been recently found that water decreases the lattice thermal conductivity of NAMs such as olivine (Chang et al. 2017), which would result in a decrease of the cooling rate of Earth. Thus, the presence of water in NAMs enhances the vigor of mantle convection and, more in general, the dynamical behavior of our planet. 


\section{THE ROLE OF HYDRATION/DEHYDRATION IN BIOLOGY}

Our current understanding of the limits of terrestrial life suggests water is one of the main requirements for the existence and survival of life on our planet and beyond (Stevenson et al. 2015; Merino et al. 2019). The molecular properties of water make it a powerful solvent, capable of interacting with a large number of macromolecules and as a stabilizing molecule in many of biology reactions (Franks 2007; Privalov and Crane-Robinson 2017) and macromolecular structures (Privalov and Crane-Robinson 2017). Additionally, water molecules also actively participate in several biological reactions either as a reactant or as a product. Hydration and dehydration reactions are indeed pervasive in several key reactions in the central metabolism. For example, condensation reactions of biological polymers, the reaction linking single monomers to create longer chains, are in fact dehydration reactions (Hulshof and Ponnamperuma 1976), and hydration/dehydration reactions feature prominently in the central metabolism, with key reactions belonging to this class present in the Tri-Carboxylic Acid (TCA) cycle and in numerous other metabolic pathways, including carbon fixation pathways responsible for primary productivity on Earth's ecosystems. Beyond the direct involvement of water as a solvent or reactant in biological reactions, water has also other indirect effects on biology and its existence. For example, the water cycle is critical in maintaining our planet habitability, and in redistributing nutrients and volatiles across the surface of the planet, both in the atmosphere and the oceans (Jelen et al. 2016). Additionally, the hydration of minerals directly influences the availability of substrates used by biology in metabolic reactions. Examples are the bioavailability of iron in aqueous media linked to the hydration and precipitation of $\mathrm{Fe}^{3+}$ as iron hydroxide $(\mathrm{FeOH})$ (Turner and Hunter 2001; Schröder et al. 2003) and the hydration of Fe-bearing minerals such as in serpentinization reactions, resulting in alkaline $\mathrm{pH}$, production of $\mathrm{H}_{2}$ and potentially low-molecular weight organic carbon (e.g., formate, methane, and a wide variety of other organic compounds) (McGlynn et al. 2020). The hydration reactions in serpentinization may have played a role in the origins of life on Earth (Russell et al. 2010; Schrenk et al. 2013) and perhaps be common throughout the cosmos, potentially sustaining extracellular life (Holm et al. 2015; Merino et al. 2019).

Water is also the electron donor in oxygenic photosynthesis (Brudvig et al. 1989; Bricker and Ghanotakis 1996), playing a key role in the extant Earth and profoundly influencing its redox evolution (Jelen et al. 2016; Moore et al. 2017). The evolution of the oxygen-evolving complex in oxygenic photosynthesis has in fact allowed to utilize the far more abundant $\mathrm{H}_{2} \mathrm{O}$ as electron donor in place of $\mathrm{H}_{2} \mathrm{~S}$ used in anoxygenic photosynthesis (Fischer et al. 2016). The resulting release of $\mathrm{O}_{2}$ as an end product of the water oxidation has dramatically altered the redox state of Earth's atmosphere and oceans and permanently changed all major biogeochemical cycles (Moore et al. 2017). Despite the key role of water in oxygenic photosynthesis, hydration/dehydration reactions are not directly involved in the light-dependent reactions, and only appear during the carbon fixation steps in the Calvin-BensonBassam cycle during the RuBisCo catalyzed hydrolysis of the 2-carboxy-3-keto-D-arabinitol 1,5 biphosphate intermediate into two 3-phosphoglycerate molecules.

The central role of hydration reactions in central metabolism is not surprising since the cytosol of organisms is aqueous and the activity of water in organisms is generally very high. Consequently, the addition of water across bonds (hydration) is generally more thermodynamically favored than elimination (dehydration or condensation). Thus, in many cases where a thermodynamically unfavorable dehydration reaction is required, biology uses some form of chemical activation to drive it. This chemical activation is often driven by phosphorylation or polyphosphorylation reactions, which are themselves typically accomplished via dehydration reactions. Thus, despite the dehydration being thermodynamically disfavored, the trade-off of higher energy hydration with lower energy dehydration allows the entire reaction to progress, a motif that is found in many biosynthetic reactions.

Despite their lower thermodynamic drive, dehydration reaction are so ubiquitous inside living cells that they largely control the origin of the intracellular water. It is estimated that in Escherichia coli, up to $70 \%$ of the intracellular water is derived directly from dehydration reactions (the so-called metabolic water) rather than by diffusion from outside (Kreuzer-Martin et al. 2005). The proportion of metabolically derived water has been shown to be directly linked to the metabolic state of the cell, further indicating the variable importance that hydration/dehydration reactions have during different phases of the cellular metabolic cycle (KreuzerMartin et al. 2005).

\section{Dehydration: Polymerization of biological molecules}

In resting cells, non-water biomass is distributed among proteins $(\sim 60 \%)$, nucleic acids $(\sim 20 \%)$, lipids $(\sim 10 \%)$, polysaccharides $(\sim 5 \%)$, and small metabolites plus ions $(\sim 5 \%)$ (Neidhardt et al. 1990; Lane and Fan 2015). Of these, the three major classes of biological macromolecules (nucleic acids, proteins, and polysaccharides) are universally polymerized by dehydrative condensation from their constituent monomers (nucleotides, amino acids, and carbohydrates) as depicted in Figure 2a, and while lipids are not polymerized by dehydration, vicinal dehydration is a critical intermediate step in lipid biosynthesis (Fig. 2b).

These reactions, however, will not occur spontaneously in an aqueous environment and are instead driven by external production of a higher energy bond that can be hydrated to offset the energy consumed to effect the polymeric dehydration, making the coupled reaction system favorable overall. In the case of carbohydrates and nucleotides, this higher energy bond comes in the form of a phosphate or polyphosphate linkage present on an energy carrying molecule such as ATP (Fig. 2b). In the case of amino acids (reaction 5), a two-step process is used where phosphate hydrolysis is used to drive the formation of a highenergy hydrolyzable thioester in the form of aminoacyl-CoA, which provides the required energy for polymerization (Fig. 2c). While lipid synthesis is a simple dehydration polymerization, the precursor step of forming a similar high energy thioester, again coupled to phosphate ester hydrolysis, is a dehydration reaction, without which lipid synthesis could not occur (Berg et al. 2002).

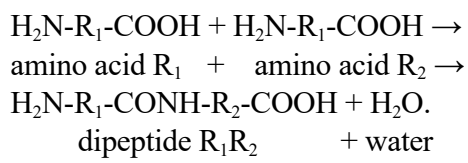


The fact that these reactions are thermodynamically unfavorable and must be driven by an external energy source is crucial to life. For proteins, nucleic acids, and polysaccharides, the sequence and bond location of each link in the polymer must be precisely controlled to achieve the intended function of the polymer. If these reactions were spontaneous, the necessary level of specificity could not be attained, and life as we know it would be impossible. A second major advantage of biopolymers having a higher energy than their constituent monomers is that polymers can be easily degraded and recycled; for example, mRNA, tRNA, and proteins are expressed transiently to achieve a needed temporary function, after which they are broken down by hydrolysis, in the reverse of the polymerization process. The monomers can then be used in new polymerizations, allowing much more efficient control of biochemical function than could be achieved without this catabolic process (Morowitz and Smith 2007).

\section{Hydration/dehydration in central metabolism}

There are numerous reactions in central metabolism, the locus of chemical reactions that supply material and energy to the living system, which involve addition or elimination of water. Core carbon metabolism uses vicinal dehydrations in the interconversion of metabolic intermediates. These include the interconversion of citrate and isocitrate by aconitase and of fumarate and malate by fumarase in the TCA cycle (Berg et al. 2002). The TCA cycle is the major energy-yielding catabolic pathway in the cells, and its intermediates are fundamental for cellular biosynthesis. Metabolic substrates as sugars, lipids, and amino acids enter the TCA cycle as acetyl-CoA and are oxidized to $\mathrm{CO}_{2}$. The cycle starts with the condensation through a hydration reaction of the acetyl group from acetyl-CoA to oxaloacetate to form citrate, which is promptly dehydrated and re-hydrated to isocitrate thanks to the action of the aconitate hydratase. This hydration/rehydration represents a critical step for the TCA cycle since citrate, a tertiary alcohol, cannot be easily oxidized. Another critical hydration step during the TCA cycle is the reverse conversion of fumarate to L-malate catalyzed by fumarate hydratase.

The inverse reactions, the dehydration of L-malate to fumarate and the hydration-dehydration of isocitrate to citrate, feature on the reductive version of the TCA cycle (rTCA), involved in the fixation of $\mathrm{CO}_{2}$ into biomass in anaerobic chemolithoautotrophic organisms (Fuchs 2011). In the Wood-Ljungdahl (WL) pathway, the reduction of carbon dioxide also requires a dehydration reaction to proceed (Ragsdale and Pierce 2008). The WL pathway is believed to be, together with the rTCA cycle, one of the oldest carbon fixation pathways in existence (Giovannelli et al. 2017) and might have played a key role in life emergence (Russell and Martin 2004). Among the key substrates of the pathway, hydrogen can be derived from the hydration reaction of olivine minerals in serpentinizing environments, thus directly linking the hydration reaction in the geosphere with the biosphere (McGlynn et al. 2020). Furthermore, in each of these pathways the numerous steps involving ATP or acetyl-CoA each entail either a hydration or dehydration reaction to proceed.

Having discussed the necessity of a high-energy hydrolyzable a

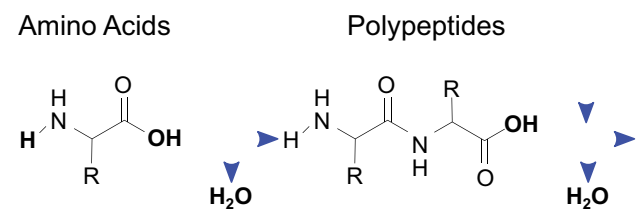

Nucleotides
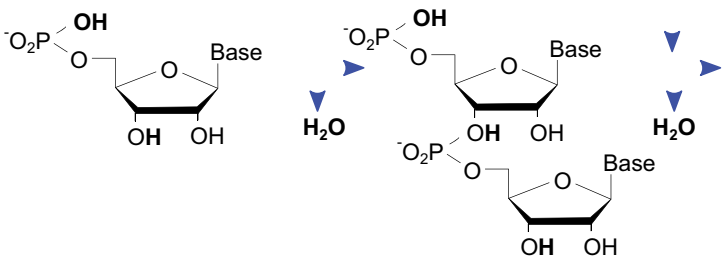

Carbohydrates<smiles>OC1CC(O)C(O)C(O)C1O</smiles>

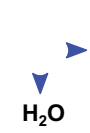<smiles>OC1CC(O)C(O)C(O)C1O</smiles>

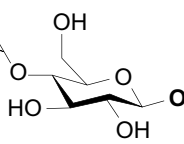

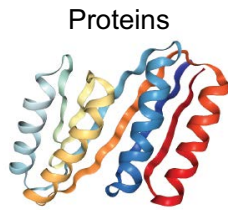

Nucleic Acids

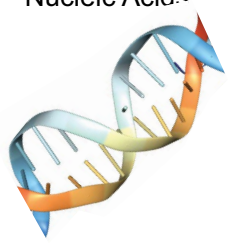

Polysaccharides

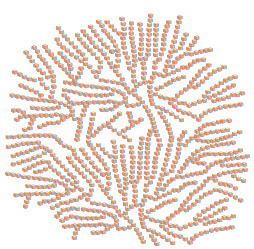

b

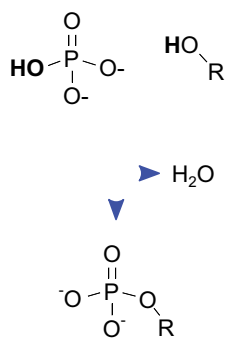<smiles>[Y]C(=O)COP(=O)(O)O</smiles><smiles>[2H]P(=O)(O)P(=O)(O)O</smiles>

C<smiles>[R]C=C[R]C=CC(=O)O</smiles>

FIGURE 2. Examples of important biochemical dehydration reactions. Reactions are depicted as schema intended to highlight the dehydration reaction and not as a strict representation of the cellular processes, which both involve enzymes and activating chemistries. (a) Anabolic dehydration reactions are responsible for the formation of each of the three major classes of biopolymers (proteins, nucleic acids, polysaccharides). The converse hydration reactions are used for the breakdown of these polymers in catabolic metabolism. (b) Phosphorylation and polyphosphorylation are dehydration reactions critical for activating other biochemical reactions, as well as cellular regulation. (c) Vicinal dehydration and hydration reactions are crucial in core metabolism. 
a

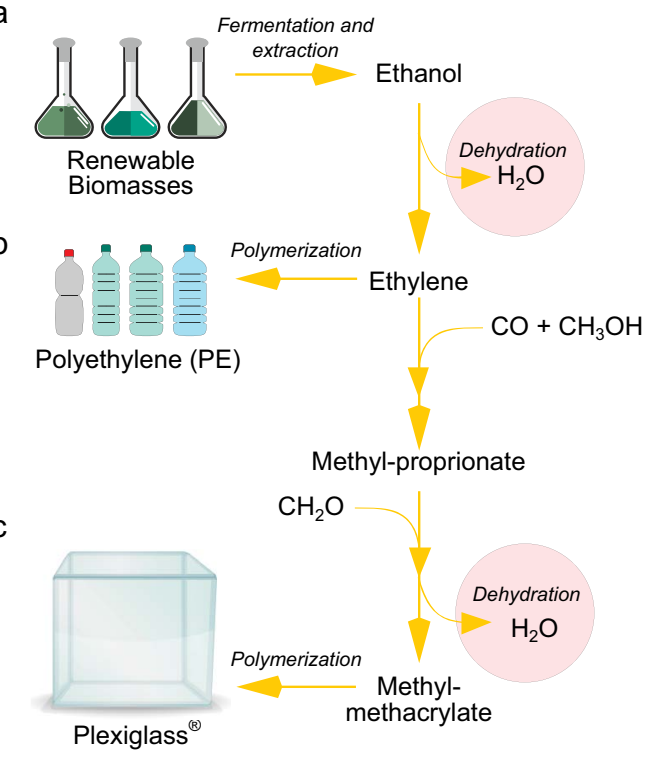

d

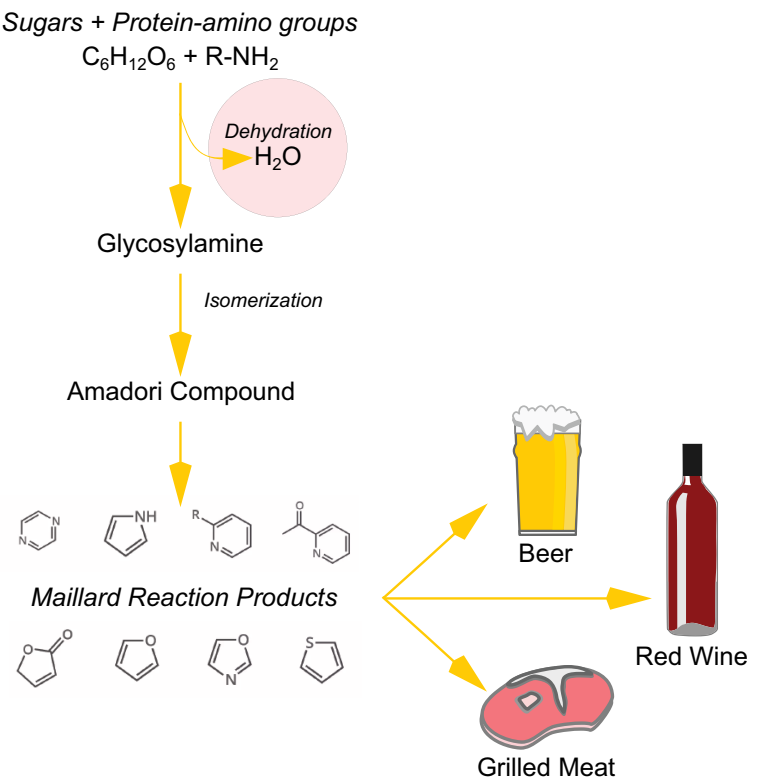

FIGURE 3. Examples of dehydration reactions in everyday life. (a-c) Pathway of industrial production of polyethylene plastic (b) and Plexiglass (c) through dehydration of bioethanol and methyl-propionate. Ethanol can be produced from renewable biomasses through fermentation (a). Following a dehydration reaction, ethanol can be converted in ethylene (b), which can be used for bioplastic production. Ethylene can be further processed to become methyl-propionate and later methyl-methacrylate through a series of reactions that include a key dehydration step. The MMA(c) becomes the precursor for the industrial production of Plexiglass. (d) Simplified reaction pathway of the Maillard reaction. The first step is a dehydration reaction involving carbohydrates and the amine groups of proteins to form glycosylamine. The diversity of Maillard reaction products obtained is responsible for the flavor in a large number of food and beverages including beer, wine, and grilled meat.

bond to drive the polymerization of biomacromolecules, it is natural to first address how these bonds are themselves created. One of the highest energy and most ubiquitous of these bonds are the polyphosphate linkages of ATP (LaRowe and Helgeson 2007; Karl and Bossard 1985). Like biopolymers, ATP is also formed through a dehydration polymerization of phosphate with ADP (Fig. 3b), though the most common mechanism is hypothesized to be physical rather than chemical (Senior et al. 2002; Štrajbl et al. 2003). Driven by a proton gradient, the ATP-synthase enzyme creates ATP squeezing ADP and phosphate together, causing a dehydration reaction. A chemical process that can produce ATP, substrate level phosphorylation, also occurs in the Krebs cycle and in glycolysis, but is less efficient (Ernster and Schatz 1981). Regardless of the source, hydrolysis of the resultant ATP molecules can provide the necessary energetic offset required to drive other unfavorable reactions. The ubiquity of ATP use throughout biochemistry is such that nearly all biochemical processes require dehydration reactions to proceed.

\section{SOCIETAL IMPACT OF HYDRATION/DEHYDRATION REACTIONS}

Hydration and dehydration reactions feature prominently in modern chemistry and are essential steps in the construction of our cities and production of numerous compounds, including various aldehydes, alcohols, and precursors of polymers. These reactions have been extensively leveraged in modern chemistry both for their applications in the synthesis of organic molecules for pharmaceutical applications and in the industrial productions of modern materials. For example, the hydration of Portland cement to form concrete is a centerpiece of the modern construction industry. This hydration is highly exothermic, similar to other hydration reactions, and part of the chemistry of which is summarized in the following reaction (reaction 6):

$$
\begin{aligned}
& 2 \mathrm{Ca}_{3} \mathrm{SiO}_{5}+7 \mathrm{H}_{2} \mathrm{O} \rightarrow \\
& \text { tricalcium silicate }+ \text { water } \rightarrow \\
& 3 \mathrm{CaO}_{2} \mathrm{SiO}_{2} \cdot 4 \mathrm{H}_{2} \mathrm{O}+3 \mathrm{Ca}(\mathrm{OH})_{2} . \\
& \text { calcium silicate hydrate }+ \text { calcium hydroxide (portlandite) }
\end{aligned}
$$

Tricalcium silicate is the main constituent of Portland cement accounting for $50-70 \%$ of the final mass, and it is one of the most reactive silicates in water (Pustovgar et al. 2016). Its hydration is responsible for the setting and initial strengthening of cement paste. Similar silicate hydration reactions, albeit very different in their molecular dynamics, are prevalent in natural and technological processes.

In addition to hydration reactions, dehydration reactions also play a key role in modern organic chemistry (Fig. 3). For example, the production of bioplastics and Plexiglass both rely on dehydration steps. One of the most commonly used routes to produce bioplastic from biomass is the dehydration of bioethanol to ethylene (Fig. 3a). Bioethanol can be produced industrially from the fermentation of biological waste products or directly using algae feedstock (Jones and Mayfield 2012). Once obtained, bioethanol can be further dehydrated to produce ethylene, the basic monomer for the production of polyethylene plastics the condensation of a reducing sugar or polysaccharide with protein or peptide, commonly known as Maillard reaction (Pastoriza et al. 2018). The Maillard reaction (Fig. 3d) is a complex set of addition, elimination, and 
rearrangement reactions that occur between reducing sugars and amines. Dehydration of simple sugars, for instance aldoses, start the process leading to $\mathrm{N}$-substituted glycosamide, which undergo Amadori rearrangement leading to 1-amino-1-deoxy-2-ketones. Furthermore, dehydration reactions of the latter lead to intermediate compounds that are part of the formation of brown substances in foods and beverages, including flavors.

\section{IMPLICATIONS}

Life on our planet needs carbon, water, and habitable conditions that are maintained through the long-term exchanges between the deep Earth and the atmosphere and hydrosphere driven by plate tectonics. Hydration/dehydration reactions play a central role in this process and accompany the most fundamental steps of the Earth evolution from its earliest stages of formation to the everyday needs of modern society. Even though some specific conditions discussed in this review are peculiar to Earth, most notably plate tectonics and life, water is among the most important targets for current and future planetary explorations and search for life beyond Earth. The role and the understanding of hydration/dehydration reactions, as well as the integration of geological, biological, and anthropic processes involving them, is therefore key in view of human habitation on other planets. As an example, Scott and Oze (2018) discuss the possibility to produce fuel and concrete in situ on Mars through hydration and dehydration reaction including serpentinization of Martian rocks, and the processing of its byproducts. A broader understanding of the role of hydration and dehydration reaction in controlling planetary process, habitability, and the emergence and evolution of biochemistry will certainly lead to more profound insight regarding the coevolution of the geosphere and biosphere.

\section{ACKNOWLEDGMENTS AND FUNDING}

We thank Patricia Barcala Dominguez for assistance in crafting Figure 3. A.V.B. was supported by ANR T-ERC grant LS 171301, MIUR grant Levi Montalcini, and by the Deep Carbon Observatory (DCO) Deep Energy community. D.G. was in part supported by NSF grant MCB 15-17567, by the "Biology Meets Subduction" grant from the Alfred P. Sloan Foundation and the DCO, and the Center for Dark Energy Biosphere Investigations (C-DEBI). D.G. and H.J.C. were supported by the ELSI Origins Network (EON), which is supported by a grant from the John Templeton Foundation. The opinions expressed in this publication are those of the authors and do not necessarily reflect the views of the John Templeton Foundation. D.G. was also partially supported a Deep Life Modeling and Visualization Fellowship, which is supported by the DCO. D.G. acknowledges the support of the project ENIGMA(NASA Astrobiology Institute cycle 8) Grant No. 80NSSC18M0093.

\section{REFERENCES CITED}

Andreani, M., Muñoz, M., Marcaillou, C., and Delacour, A. (2013) $\mu$ XANES study of iron redox state in serpentine during oceanic serpentinization. Lithos, 178, 70-83.

Berg, J.M., Tymoczko, J.L., and Stryer, L. (2002) Biochemistry, 5th ed. Freeman.

Bolfan-Casanova, N. (2005) Water in the Earth's mantle. Mineralogical Magazine, 69, 229-257.

Brearley, A.J. (2006) The action of water. In D.S. Lauretta and H.J. McSween, Eds., Meteorites and the Early Solar System II, p. 587-624. The University of Arizona Press, Tucson.

Bricker, T.M., and Ghanotakis, D.F. (1996) Introduction to oxygen evolution and the oxygen-evolving complex. In D.R. Ort, C.F. Yocum, and I.F. Heichel, Eds., Oxygenic Photo2synthesis: The Light Reactions, pp. 113-136. Springer.

Bricker T.M., Ghanotakis D.F. (1996) Introduction to Oxygen Evolution and the OxygenEvolving Complex. In: (eds) Oxygenic Photosynthesis: The Light Reactions. Advances in Photosynthesis and Respiration, vol 4. Springer, Dordrecht

Brudvig, G.W., Beck, W.F., and Paula, J.C. (1989) Mechanism of photosynthetic water oxidation. Annual Review of Biophysics and Biophysical Chemistry, 18(1), 25-46.

Caldeira, K., and Wickett, M.E. (2003) Anthropogenic carbon and ocean pH. Nature, 425,365 .

Campbell, I.H., and Taylor, S.R. (1983) No water, no granites - No oceans, no continents. Geophysical Research Letters, 10, 1061-1064.

Chang, Y.-Y., Hsieh, W.-P., Tan, E., and Chen, J. (2017) Hydration-reduced lattice thermal conductivity of olivine in Earth's upper mantle. Proceedings of the National Academy of Sciences, 114, 4078-4081.

Chappell, B.W., and White, A.J.R. (1992) I- and S-type granites in the Lachlan Fold Belt. Transactions of the Royal Society of Edinburgh: Earth Sciences, 83, 1-26.

Ciesla, F., and Lauretta, D. (2005) Radial migration and dehydration of phyllosilicates in the solar nebula. Earth and Planetary Science Letters, 231, 1-8.

Dasgupta, R. (2013) Ingassing, storage, outgassing of terrestrial carbon through geologic time. Reviews in Mineralogy and Geochemistry, 75, 183-229.

Demouchy, S., and Bolfan-Casanova, N. (2016) Distribution and transport of hydrogen in the lithospheric mantle: A review. Lithos, 240, 402-425.

Edmonds, M., Tutolo, B., Iacovino, K., and Moussallam, Y. (2020) Magmatic carbon outgassing and uptake of $\mathrm{CO}_{2}$ by alkaline waters. American Mineralogist, 105(1), 28-34

Elkins-Tanton, L.T. (2012) Magma oceans in the inner solar system. Annual Review of Earth and Planetary Science, 40, 113-139.

Ernster, L., and Schatz, G. (1981) Mitochondria: a historical review. Journal of Cell Biology, 91 (3), 227s-255s.

Escartin, J., Hirth, G., and Geology, B.E. (2001) Strength of slightly serpentinized peridotites: Implications for the tectonics of oceanic lithosphere. Geology, 29, 1023.

Faccenda, M. (2014) Water in the slab: A trilogy. Tectonophysics, 614, 1-30.

Fischer, W.W., Hemp, J., and Johnson, J.E. (2016) Evolution of oxygenic photosynthesis. Annual Review of Earth and Planetary Sciences, 44(1), 647-683.

Franks, F. (2007) Water: A matrix of life. Royal Society of Chemistry.

Fuchs, G. (2011) Alternative pathways of carbon dioxide fixation: Insights into the early evolution of life? Annual Review of Microbiology, 65(1), 631-658.

Fumagalli, P., and Poli, S. (2005) Experimentally determined phase relations in hydrous peridotites to $6.5 \mathrm{GPa}$ and their consequences on the dynamics of subduction zones. Journal of Petrology, 46, 555-578.

Gail, H.-P., and Trieloff, M. (2017) Spatial distribution of carbon dust in the early solar nebula and the carbon content of planetesimals. Astronomy \& Astrophysics, 606 , A16-18.

Giovannelli, D., Sievert, S.M., Hügler, M., Markert, S., Becher, D., Schweder, T., and Vetriani, C. (2017) Insight into the evolution of microbial metabolism from the deepbranching bacterium, Thermovibrio ammonificans. ELife, 6, e18990.

Gorman, P.J., Kerrick, D.M., and Connolly, J.A.D. (2006) Modeling open system metamorphic decarbonation of subducting slabs. Geochemistry, Geophysics, Geosystems, 7(4), 1-21.

Green, D.H. (2015) Experimental petrology of peridotites, including effects of water and carbon on melting in the Earth's upper mantle. Physics and Chemistry of Minerals, 42, 95-122.

Grove, T.L., and Kinzler, R.J. (1986) Petrogenesis of andesites. Annual Review of Earth and Planetary Science, 14, 417-454.

Hawkesworth, C.J., Gallagher, K., Herget, J.M., and McDermott, F. (1993) Mantle and slab contributions in arc magmas. Annual Review of Earth and Planet Science, 21, 175-204.

Henning, T., and Semenov, D. (2013) Chemistry in protoplanetary disks. Chemical Reviews, 113, 9016-9042.

Hermann, J., and Spandler, C. (2008) Sediment melts at sub-arc depths: an experimental study. Journal of Petrology, 49, 717-740.

Hilairet, N., Reynard, B., Wang, Y., Daniel, I., and Merkel, S. (2007) High-pressure creep of serpentine, interseismic deformation, and initiation of subduction. Science, 318, 1910-1913.

Holm, N.G., Oze, C., Mousis, O., Waite, J.H., and Guilbert-Lepoutre, A. (2015) Serpentinization and the formation of $\mathrm{H}_{2}$ and $\mathrm{CH}_{4}$ on celestial bodies (planets, moons, comets). Astrobiology, 15(7), 587-600.

Hulshof, J., and Ponnamperuma, C. (1976) Prebiotic condensation reactions in an aqueous medium: A review of condensing agents. Origins of Life, 7(3), 197-224.

Hyndman, R.D., and Peacock, S.M. (2003) Serpentinization of the forearc mantle. Earth and Planetary Science Letters, 212(3-4), 417-432.

Izodoro, A., de Souza Torres, K., Winter, O.C., and Haghighipour, N. (2013)A compound model for the origin of Earth's water. The Astrophysical Journal, 767, 54. DOI: https:// doi.org/10.1088/0004-637X/767/1/54

Jarrard, R.D. (2003) Subduction fluxes of water, carbon dioxide, chlorine, and potassium. Geochemistry, Geophysics, Geosystems, 4, 1-50.

Jelen, B.I., Giovannelli, D., and Falkowski, P.G. (2016) The role of microbial electron transfer in the coevolution of the biosphere and geosphere. Annual Review of Microbiology, 70(1), 45-62.

Jones, C.S., and Mayfield, S.P. (2012) Algae biofuels: Versatility for the future of bioenergy. Current Opinion in Biotechnology, 23(3), 346-351.

Karato, S.I. (2006) Remote sensing of hydrogen in Earth's mantle. Reviews in Mineralogy and Geochemistry, 62, 343-375.

Karl, D.M., and Bossard, P. (1985) Measurement and significance of ATP and adenine nucleotide pool turnover in microbial cells and environmental samples. Journal of Microbiological Methods, 3, 125-139.

Katayama, I., and Nakashima, S. (2003) Hydroxyl in clinopyroxene from the deep subducted crust: Evidence for $\mathrm{H}_{2} \mathrm{O}$ transport into the mantle. American Mineralogist, 88, 229-234.

Katayama, I., Nakashima, S., and Yurimoto, H. (2006) Water content in natural eclogite and implication for water transport into the deep upper mantle. Lithos, 86(3-4), 245-259.

Kelemen, P.B., and Manning, C.E. (2015) Reevaluating carbon fluxes in subduction zones, what goes down, mostly comes up. Proceedings of the National Academy 
of Sciences, 112, E3997-E4006.

Kelemen, P.B., Matter, J., Streit, E.E., Rudge, J.F., Curry, W.B., and Blusztajn, J. (2011) Rates and mechanisms of mineral carbonation in peridotite: natural processes and recipes for enhanced, in situ $\mathrm{CO}_{2}$ capture and storage. Annual Reviews in Earth and Planetary Science, 39, 545-576.

King, R.L., Kohn, M.J., and Eiler, J.M. (2003) Constraints on the petrologic structure of the subduction zone slab-mantle interface from Franciscan Complex exotic ultramafic blocks. Geological Society of America Bulletin, 115, 1097-1109.

King, H.E., Stimpfl, M., Deymier, P., Drake, M.J., Catlow, C.R.A. Putnis, A., and de Leeuw, N.H. (2010) Computer simulations of water interactions with low-coordinated forsterite surface sites: implications for the origin of water in the inner solar system. Earth and Planetary Science Letters, 300, 11-18.

Klein, F., Bach, W., Jons, N., McCollom, T., Moskowitz, B., and Berquo, T. (2009) Iron partitioning and hydrogen generation during serpentinization of abyssal peridotites from $15^{\circ} \mathrm{N}$ on the Mid-Atlantic Ridge. Geochimica et Cosmochimica Acta, 73, 6868-6893.

Kohlstedt, D.L. (2006) The role of water in high-temperature rock deformation. Reviews in Mineralogy and Geochemistry, 62, 377-396.

Kreuzer-Martin, H.W., Ehleringer, J.R., and Hegg, E.L. (2005) Oxygen isotopes indicate most intracellular water in log-phase Escherichia coli is derived from metabolism. Proceedings of the National Academy of Sciences, 102(48), 17337-17341.

Kump, L.R., Brantley, S.L., and Arthur, M.A. (2000) Chemical weathering, atmospheric $\mathrm{CO}_{2}$, and climate. Annual Reviews in Earth and Planetary Science, 28, 611-667.

Kump, L.R., Bralower, T.J., and Ridgwell, A. (2009) Ocean acidification in deep time. Oceanography, 22, 94-107.

Lane, A.N., and Fan, T. W-M. (2015) Regulation of mammalian nucleotide metabolism and biosynthesis. Nucleic Acids Research, 43 (4), 2466-2485.

LaRowe, D.E., and Helgeson, H.C. (2007) Quantifying the energetics of metabolic reactions in diverse biogeochemical systems: electron flow and ATP synthesis. Geobiology, 5(2), 153-168.

Li, J., Redfern, S.A.T., and Giovannelli, D. (2019) Introduction: Deep carbon cycle though five reactions. American Mineralogist, 104, 465-467.

Macdonald, F.A., Swanson-Hysell, N.L., Park, Y., Lisiecki, L., and Jagoutz, O. (2019) Arc-continent collisions in the tropics set Earth's climate state, Science, 364, 181-184.

Marty, B., Avice, G., Sano, Y., Altwegg, K., Balsiger, H., Hässig, M., Morbidelli, A., Mousis, O., and Rubin, M. (2016) Origins of volatile elements (H, C, N noble gases) on Earth and Mars in light of recent results from the ROSETTA cometary mission. Earth and Planetary Science Letters, 441, 91-102.

McGlynn, S.E., Glass, J.B., Johnson-Finn, K., Klein, F., Sanden, S.A., Schrenk, M.O., Ueno, Y., and Vitale-Brovarone, A. (2020) Hydrogenation reactions of carbon on Earth: Linking methane, and margarine, and life. American Mineralogist, 105, 599-608.

Merino, N., Aronson, H.S., Bojanova, D.P., Feyhl-Buska, J., Wong, M.L., Zhang, S., and Giovannelli, D. (2019) Living at the extremes: Extremophiles and the limits of life in a planetary context. Frontiers in Microbiology, 10.

Moore, E.K., Jelen, B.I., Giovannelli, D., Raanan, H., and Falkowski, P.G. (2017) Metal availability and the expanding network of microbial metabolisms in the Archaean eon. Nature Geoscience, 10(9), 629-636.

Morbidelli, A., Lunine, J.I., O’Brien, D.P., Raymond, S.N., and Walsh, K.J. (2012) Building terrestrial planets. Annual Review of Earth and Planetary Science, 40, 251-275.

Morowitz, H., and Smith, D.E. (2007) Energy flow and the organization of life. Complexity, 13, 1, 51-59.

Neidhardt, F.C., Ingraham, J.L., and Schaechter, M. (1990) Physiology of the Bacterial Cell: A Molecular Approach, vol. 20. Sinauer Associates.

Nursten, H.E. (2007) The Maillard Reaction, p. 1-214. Cambridge.

O'Brien, D.P., Izidoro, A., Jacobson, S.A., Raymond, S.N., and Rubie, D.C. (2018) The delivery of water during terrestrial planet formation. Space Science Reviews, 21447.

Padrón-Navarta, J.-A., and Hermann, J. (2017) A subsolidus water solubility equation for the Earth's upper mantle. Journal of Geophysical Research, 122, 9862-9880.

Padrón-Navarta, J.A., Lopez Sanchez-Vizcaino, V., Hermann, J., Connolly, J.A.D., Garrido, C.J., Gomez-Pugnaire, M.T., and Marchesi, C. (2013) Tschermak's substitution in antigorite and consequences for phase relations and water liberation in high-grade serpentinites. Lithos, 178, 186-196.

Pastoriza, S., Quesada, J., and Rufián-Henares, J.A. (2018) Lactose and oligosaccharides: Maillard reaction. In: Reference Module in Food Science, pp. 1-19. Elsevier. https:// doi.org/10.1016/B978-0-08-100596-5.22552-3

Pearson, D.G., Brenker, F.E., Nestola, F., McNeill, J., Nasdala, L., Hutchison, M.T., Matveev, S., Mather, K., Silversmit, G., Schmitz, S., Vekemans, B., and Vincze, L., (2014) Hydrous mantle transition zone indicated by ringwoodite included within diamond. Nature, 507, 221-224.

Plank, T., Kelley, K.A., Zimmer, M.M., Hauri, E.H., and Wallace, P.J. (2013) Why do mafic arc magmas contain $\sim 4 \mathrm{wt} \%$ water on average? Earth and Planetary Science Letters, 364, 168-179.

Privalov, P.L., and Crane-Robinson, C. (2017) Role of water in the formation of macromolecular structures. European Biophysics Journal, 46(3), 203-224.

Pustovgar, E., Sangodkar, R.P., Andreev, A.S., Palacios, M., Chmelka, B.F., Flatt, R.J., and d'Espinose de Lacaillerie, J.-B. (2016) Understanding silicate hydration from quantitative analyses of hydrating tricalcium silicates. Nature Communications, 7 , 10952. doi: $10.1038 /$ ncomms 10952.

Ragsdale, S.W., and Pierce, E. (2008) Acetogenesis and the Wood-Ljungdahl pathway of $\mathrm{CO}_{2}$ fixation. Biochimica et Biophysica Acta—Proteins and Proteomics, 1784 $12,1873-1898$.

Raymo, M.E., Ruddiman, W.F., and Froelich, P.N. (1988) Influence of late Cenozoic mountain building on ocean geochemical cycles. Geology, 16, 649-653.

Roggensack, K., Hervig, R.L., McKnight, S.B., and Williams, S.N. (1997) Explosive basaltic volcanism from Cerro Negro volcano: influence of volatiles on eruptive style. Science, 277, 1639-1642.

Rubey, W.W. (1951) Geologic history of sea water: an attempt to state the problem Geological Society of America Bulletin, 62(9), 1111-1148.

Russell, M.J., and Martin, W. (2004) The rocky roots of the acetyl-CoA pathway. Trends in Biochemical Sciences, 29(7), 358-363.

Russell, M.J., Hall, A.J., and Martin, W. (2010) Serpentinization as a source of energy at the origin of life: serpentinization and the emergence of life. Geobiology, 8, 355-371.

Schmidt, M.W., and Poli, S. (1998) Experimentally based water budgets for dehydrating slabs and consequences for arc magma generation. Earth and Planetary Science Letters, 163, 361-379.

Schrenk, M.O., Brazelton, W.J., and Lang, S.Q (2013) Serpentinization, carbon, and deep life. Reviews in Mineralogy and Geochemistry, 75, 575-606.

Schröder, I., Johnson, E., and de Vries, S. (2003) Microbial ferric iron reductases. FEMS Microbiology Reviews, 27(2-3), 427-447.

Schulte, M., Blake, D., Hoehler, T., and McCollom, T.M. (2006) Serpentinization and its implications for life on the early Earth and Mars. Astrobiology, 60, 364-376.

Scott,A.N., and Oze, C. (2018) Constructing Mars: Concrete and energy production from serpentinization Products. Earth and Space Science, 5(8), 364-370.

Sekine, T., Meng, C.M., Zhu, W.J., and He, H.L. (2012) Direct evidence for decomposition of antigorite under shock loading. Journal of Geophysical Research, 117, B03212.

Senior, A.E., Nadanaciva, S., and Weber, J. (2002) The molecular mechanism of ATP synthesis by F1F0-ATP synthase. Biochimica et Biophysica Acta-Bioenergetics, $1553,3,188-211$.

Smith, E.M., Shirey, S.B., Nestola, F., Bullock, E.S., Wang, J., Richardson, S.H., and Wang, W. (2016) Large gem diamonds from metallic liquid in Earth's deep mantle. Science, 354, 1403-1405.

Smith, E.M., Shirey, S.B., Richardson, S.H., Nestola, F., Bullock, E.S., Wang, J., and Wang, W. (2018) Blue boron-bearing diamonds from Earth's lower mantle. Nature, 1-14.

Smyth, J.R., and Jacobsen, S.D. (2006) Nominally anhydrous minerals and Earth's deep water cycle. In S.D. Jacobsen and S. Van Der Lee, Eds., Earth's Deep Water Cycle, vol. 320, pp. 1-11. American Geophysical Union, Washington, D.C.

Smyth, J.R., Rossman, G.R., and Bell, D.R. (1991) Incorporation of hydroxyl in upper mantle clino-pyroxenes. Nature, 351, 732-735.

Smyth, J.R., Holl, C.M., Frost, D.J., Jacobsen, S.D., Langenhorst, F., and McCammon, C.A. (2003) Structural systematics of hydrous ringwoodite and water in Earth's interior. American Mineralogist, 88(10), 1402-1407.

Stevenson, A., Cray, J.A., Williams, J.P., Santos, R., Sahay, R., Neuenkirchen, N., McClure, C.D., Grant, I.,R., Houghton, J.D.R., Quinn, J.P., and others. (2015) Is there a common water-activity limit for the three domains of life. The ISME Journal, 9 , 1333-1351.

Stewart, E.M., Ague, J.J., Ferry, J.M., Schiffries, C.M., Tao, R.B., Isson, T.T., and Planavsky, N.J. (2019) Carbonation and decarbonation reactions: Implications for planetary habitability. American Mineralogist, 104, 1369-1380.

Štrajbl, M., Avital, S., and Arieh, W. (2003) Converting conformational changes to electrostatic energy in molecular motors: The energetics of ATP synthase. Proceedings of the National Academy of Sciences, 100, 25, 14834-14839.

Thomas, S.M., Jacobsen, S.D., Bina, C.R., Reichart, P., Moser, M., Hauri, E.H., KochMüller, M., Smyth, J.R., and Dollinger, G. (2015) Quantification of water in hydrous ringwoodite. Frontiers in Earth Science, 2, 1-10.

Tschauner, O., Huang, S., Greenberg, E., Prakapenka, V.B., Ma, C., Rossman, G.R., and Tait, K. (2018) Ice-VII inclusions in diamonds: Evidence for aqueous fluid in Earth's deep mantle. Science, 359, 1136-1139.

Turner, D.R., and Hunter, K.A. (Eds.) (2001) The Biogeochemistry of Iron in Seawater, vol. 6. Wiley.

Ulmer, P., and Trommsdorff, V. (1995) Serpentine stability to mantle depths and subduction-related magmatism. Science, 268, 858-861.

Ulmer, P., Kaegi, R., and Müntener, O. (2018) Experimentally derived intermediate to silica-rich arc magmas by fractional and equilibrium crystallization at $1.0 \mathrm{GPa}$ an evaluation of phase relationships, compositions, liquid lines of descent and oxygen fugacity. Journal of Petrology, 59, 11-58.

Vitale Brovarone, A., and Beyssac, O. (2014) Lawsonite metasomatism: A new route for water to the deep Earth. Earth and Planetary Science Letters, 393, 275-284.

Wada, I., Behn, M.D., and Shaw, A.M. (2012) Effects of heterogeneous hydration in the incoming plate, slab rehydration, and mantle wedge hydration on slab-derived $\mathrm{H}_{2} \mathrm{O}$ flux in subduction zones. Earth and Planetary Science Letters, 353-354, 60-71.

Zega, T.J., Garvie, L.A.J., and Buseck, P.R. (2003) Nanometer-scale measurements of iron oxidation states of cronstedtite from primitive meteorites. American Mineralogist, $88,1169-1172$.

MANUSCRIPT RECEIVED NOVEMBER 25, 2019

MANUSCRIPT ACCEPTED MARCH 18, 2020

MANUSCRIPT HANDLED BY SIMON REDFERN 